\title{
Crucial predicting factors of under-five mortality in Sierra Leone
}

\author{
Lubna Naz ${ }^{\mathrm{a}, *}$, Kamalesh Kumar Patel ${ }^{\mathrm{b}}$, Ifeoma Evan Uzoma ${ }^{\mathrm{c}}$ \\ ${ }^{a}$ Department of Economics, University of Karachi, Karachi, 75290, Pakistan \\ ${ }^{\mathrm{b}}$ Indian Institute of Health Management Research (IIHMR), Jaipur, 302029, India \\ ${ }^{\mathrm{c}}$ Department of Geography and Natural Resources and Management, University of Uyo, Akwa IBOM State, Nigeria
}

\section{A R T I C L E I N F O}

\section{Keywords:}

Birth-spacing

Birth size

Cox-proportional hazards model

Under-five mortality

\begin{abstract}
A B S T R A C T
Introduction: Sierra Leone includes in countries which exhibit the highest prevalence of under-five mortality in the world. A range of factors are known to have challenged the under-five survival in the country; some comprise outbreak of epidemics, socioeconomic inequalities, regional disparities, and unsuccessful implementation of healthcare initiatives. The present study aims to identify crucial predictors of under-five survival. Methods: This paper used the Sierra Leone Demographic and Health Survey (SLDH, 2013). A Cox Proportional Hazards Model was applied to the sample of 24,742 children to analyze the adjusted and unadjusted hazards ratio of crucial risk factors of under-five mortality.

Results: The results show that birth interval and birth size are leading risk factors of under-five mortality in Sierra Leone. A birth spacing exceeding three years is associated with the lowest risk compared to 2-3 years and lesser than two years. The average or larger birth size has the lowest hazards followed by smaller than average, and the magnitude of the effect remains the same in adjusted and unadjusted models. The wealth status is a crucial predictor only in the unadjusted model. Mother's age, sex of the child, and a number of children in the household are significant covariates.

Conclusion: Given the research findings, this study recommends for re-orientation of reproductive healthcare strategies to target the younger mother and birth-spacing, and integration of nutrition-related interventions with the maternal healthcare initiatives to influence the child birth-size.
\end{abstract}

\section{Introduction}

For the past two decades, a substantial decline has occurred in the under-five mortality worldwide; as it declined from 93 per 1000 live births in 1990 to 39 per 1000 live births in 2017. However, SubSaharan Africa has made the dawdling progress in achieving the desired decline in line with Millennium Development Goal 4 (by two-thirds) during 1990-2015. The under-five mortality has declined at $3.2 \%$, which is the lowest among all regions of the world in 1990-2017. ${ }^{1}$

Sierra Leone is amongst ten countries which exhibit the highest prevalence of under-five mortality in the region as well as in the world in 2018. As follows: Somalia (121/1000); Nigeria (119/1000); Chad (118/1000), Central African Republic (116/1000); Sierra Leone (105/ 1000), Guinea (100/1000); South Sudan (98/1000); Mali (97/1000); Benin (92/1000); Democratic Republic of Congo (88/1000), (World Bank Development Indicators, 2018) ${ }^{1}$ It also ranks the highest in maternal mortality (1120/10000) worldwide in $2018,{ }^{2}$ and one-third of total maternal deaths are related to pre and post-delivery complications (SDHS, 2013).

For tackling with multiple challenges in healthcare, the country launched a series of reforms such as "the National Health Sector Strategic Plan-NHSSP (2010-2015), Agenda for Prosperity-AFP (2013-2018), the Free Health Care Initiative-FHCI (2010), and more recently Basic Package of Essential Health Services-BPEHS (2015-2020), and Health Sector Recovery Plan-HSRP (2015-220)". However, the reforms have made trivial contributions towards achieving health-related Sustainable Development Goals. ${ }^{2-6}$

Previous studies indicate that the leading causes of childhood mortality have been more or less the same in Sierra Leone for many decades. During 1969-1979, infectious diseases accounted for over fifty percent of total childhood deaths. In the early 80s, the leading causes included child delivery by unprofessional staff, poor child healthcare practices and the inadequate nutritional status of mother. ${ }^{7}$ Moreover, some prominent factors comprised maternal age and number of living

\footnotetext{
* Corresponding author.

E-mail addresses: lubnanaz@uok.edu.pk (L. Naz), kamaleshkumar.patel@gmail.com (K.K. Patel), uzomaifeoma20@gmail.com (I.E. Uzoma).

${ }^{1}$ https://data.worldbank.org/indicator/SH.DYN.MORT.

${ }^{2}$ https://data.worldbank.org/indicator/SH.STA.MMRT.
} 
children, paternal education, religion, women's age at marriage, and parent's occupation. ${ }^{8}$

Recently, an assessment of the determinants of childhood malnutrition and mortality suggests that mother's education, population density, differential gender needs of children, nutritional insufficiency, inadequate intake of micronutrients, and poor maternal healthcare are essential risk factors of child mortality in Sierra Leone. ${ }^{9}$ Furthermore, the inadequate social infrastructure, poor medical supplies, shortage in the healthcare financing, lack of adequate monitoring and evaluation of health programs, and battling with epidemics and consequently civil fatalities, may be included among implicit causes of persistently higher prevalence of childhood mortality. ${ }^{6,10,11}$

To the best of the knowledge of authors, the few studies have analyzed the crucial factors of under-five mortality in countries with the highest prevalence of under-five mortality. ${ }^{9,12-17}$ Hence, by using available data and statistical methods, this paper attempts to pinpoint crucial risk factors of under-five mortality in Sierra Leone. The study hypothesizes that birth interval, birth size, and wealth status are leading predictors of under-five mortality. Moreover, the paper analyzes risk factors related to mother, child and household.

\section{Materials and methods}

\subsection{Study setting}

The empirical assessment of under-five mortality is based on Sierra Leone. The country shares borders with Guinea on North and Northeast and with Liberia on East and Southeast. There are four regions, 14 districts and 149 chiefdoms. The overall population of the country is 7.6 million, of which $58 \%$ is living in rural areas and earn a livelihood from agriculture. Around half of the population (52\%) lives below the poverty threshold (USD 1.90 a day). Gross Domestic Per-Capita Income (PPP) of Sierra Leone is 1530 US dollars which put it into the group of lower-income countries (UNESCO, 2017). ${ }^{3}$ The life expectancy at birth is 54 years, which is lower than the average (61 years) of the SubSaharan Africa (World Bank, 2017).

\subsection{Data and sampling}

This paper used the Sierra Leone Demographic and Health Survey, 2013. The sample frame used in the survey (SLDHS, 2013) was stratified into urban and rural domains and further into regions and districts to get an adequate representation of each strata. The selection of the sample involved two phases. At first, the primary sample units (PSUs) were chosen from the list of enumeration blocks (EBs) of the "Sierra Leone General Population and Housing Census-2004". In total, 435 primary sampling units, including 277 rural and 158 urban, were selected. In the next phase, 30 households were systematically picked from each cluster or PSU. To analyze the under-five mortality, the present study used a sample of 24,742 under-five children who had taken birth in10 years before the survey (SLDHS, 2013).

\subsection{Description of variables}

This paper followed analytical and empirical literature on childhood mortality to select crucial variables for the child survival analysis. ${ }^{17-21,24}$

This study followed "UNICEF definition of under-five mortality", as follows, "probability of dying between birth and exactly five years of age expressed per 1000 livebirths" ${ }^{4}$ The extensive information from birth histories of women aged 15-49 was used to compute the hazard ratio of dying between birth and exactly five years of age. Finally, the

\footnotetext{
${ }^{3}$ http://uis.unesco.org/en/country/sl.

${ }^{4}$ https://www.unicef.org/infobycountry/stats_popup1.html.
}

hazard ratio was used as an outcome variable.

\subsection{Crucial predictors}

The study hypothesized some crucial risk factors of childhood survival, which were birth interval, birth size, and wealth status. The birth interval was measured using three orderings, as follows, $<2$ years; 2-3 years; and $>3$ years. The variable is in line with guidelines of "World Health Organization (WHO) which stress upon maintaining spacing or gap of at least three to five years between two consecutive births to diminish health risks to newborn and mothers". Moreover, previous studies suggest that the birth intervals of specific ranges, $<36$ months and $>60$ months, are associated with higher hazards of mortality and morbidity among infants. ${ }^{22,23}$

The birth size of the child was measured as a categorical variable. Three groups were formed: very small; small; and average or larger. In developing countries, it is evident that birth weight is one of the noteworthy determinants of child survival, nutritional status, and morbidity. ${ }^{18}$ This paper used birth size as a crucial risk factor of under-five mortality in Sierra Leone (see Model 3 in Table 2).

SLDH, 2013 provides information on household wealth index. In survey, the index was computed by employing an extensive information on household assets, dwelling characteristics, drinking water sources, type of toilet facility, and other characteristics of the household. The five quintiles of the wealth index were formed, as follows; the poorest, poor, middle, rich, and the richest. This paper joined the first two quintiles in one group and named it "poor" and combined the last two quintiles in another group, termed as "rich". However, the middle (third quintile) was used as given by the wealth index. Henceforth, three groups were used: poor, middle, and rich to represent the wealth status.

\subsection{Proximate factors}

The paper used a range of explanatory variables relating to maternal, child and household characteristics. Mother's education was measured as a categorical variable: educated and not educated. The former comprised mothers who had some qualification, ranging from primary to post-graduate whereas the latter included those who did not have any education. The working status of the mother was examined as a binary variable (0/1); where 1 means currently-working mothers and 0 denotes not working.

Empirical evidence reveals under-five children whose mothers are either younger or older are related to higher risk of death. ${ }^{25}$ SLDHS, 2013 indicates that the median age of the women at first birth was 19.5 years in Sierra Leone. Therefore, the study used a closer cutoff age (18 years) of the women.

This study used information on the antenatal care in the simplified manner by constructing the binary variable $(0 / 1)$, where 1 shows that pregnant women had visited the service provider at least once, and 0 otherwise. Moreover, the postnatal care was measured as a binary variable $(0 / 1)$, where 1 was showing that postnatal care was received, and 0 implying not received. The institutional delivery (ID) was a binary variable.

The study measured the sex of a child as a categorical variable (male/female). In household-related variables, the study formed three categories of the number of children, as follows, 1-2, 3-4, and 5 and more children. Moreover, the paper measured the type of residence as a categorical variable; rural households were coded as 1 and urban as 2 .

\subsection{Model}

The paper employed a Person's Chi-square test to evaluate the relationship between each of the explanatory variables and the outcome variable. The underlying null-hypothesis ( $\mathrm{HO}$ ) of the test is that two variables are not associated while the alternate hypothesis (Ha) 
presumes the opposite. The associations were checked at p-value $<$ 0.05 , p-value $<0.001$, and p-value $<0.1$. Moreover, the study followed a Cox Proportional Hazards Model, ${ }^{26}$ a multivariate regression, to analyze the likely effect of the risk factors on under-five mortality. The Cox model can be expressed as,

$h(t, X)=h_{0}(t) \varphi(X)$

where

$\phi(X)=\exp \sum_{1=1}^{p} \beta_{i} x_{i}$

After replacing Equation (2) in Equation (1) for the value of $\phi(X)$ gives the following,

$h_{i}(t)=h_{0}(t) \exp \sum_{i=1}^{p} \beta_{i} x_{i}$

In equation (3), $h_{i}(t)$ is the hazard at the time $t$ of ith child, $\beta_{i}=\beta_{1}, \beta_{2}, \ldots . ., \beta_{p}$ are regression coefficients of explanatory variables, $x_{i}$ is a vector of regressors or risk factors, and $h_{0}(t)$ is the baseline hazard function. The proportional form can be obtained by dividing equation (3) by $h_{0}(t)$, as follows,

$\frac{h_{i}(t)}{h_{0}(t)}=\exp \sum_{i=1}^{p} \beta_{i} x_{i}$

Taking logarithms of equation (4) gives,

$\ln \left(\frac{h_{i}(t)}{h_{0}(t)}=\beta_{1} x_{1}, \ldots \ldots, \beta_{p} x_{p}\right.$

Equation (5) shows that for each value of $t$, the ith individual hazard function is proportional to the baseline function. The Cox model encompasses both parametric and non-parametric features. Therefore, the estimates drawn from the Cox regression approximate the logit or Probit model.

\section{Results}

\subsection{Bivariate analysis}

The results of Bivariate analysis are presented in Table 1. At $\mathrm{p}<0.001$ significance level, the under-five mortality was lower among educated mothers (139/1000), currently not working (131/ $1000)$, and above 18 years of age at the time of first birth (145/1000). At the same significance level, under-five mortality was lower among households with more than five children (96/1000). Mothers who had a birth interval of more than three years were associated with lower risk (96/1000). The children with average or larger birth size were associated with a lower risk (94/1000). The lower risk of under-five deaths was observed among rich (142/1000), and among households which have urban residence $(142 / 1000)$.

\subsection{Multivariate analysis}

The results of the adjusted and un-adjusted hazards of crucial risk factors are given in Table 2. All crucial risk factors, except wealth status, were statistically significant in both models. Amidst birth intervals, the risk of under-five deaths was lower for birth intervals of three years or more (HR $=0.70,95 \%$ CI: 0.49-0.98) while the effect of 2-3 years was statistically insignificant in the adjusted model, see Model 1. The smaller than average and average or larger birth size had significant effects on under-five child survival compared to the basegroup.

The effect of wealth status, another crucial risk factor, was not statistically significant in the adjusted model. It might be due to the effect of other covariates which would have off-set the predicting effect of household wealth on under-five mortality.
Table 1

Prevalence of under-five mortality by crucial and proximate factors in Sierra Leone, 2013.

\begin{tabular}{|c|c|c|c|}
\hline \multirow[t]{2}{*}{ Crucial and Proximate Factors } & \multicolumn{3}{|c|}{ Under-five mortality (per 1000 live birth) } \\
\hline & $\mathrm{N}$ & Prevalence & p-value \\
\hline \multicolumn{4}{|l|}{ Mother Education } \\
\hline Not Educated & 2966 & 161.8 & $\mathrm{p}<0.001$ \\
\hline Educated & 891 & 139.0 & \\
\hline \multicolumn{4}{|l|}{ Mother's job status } \\
\hline Not Working & 506 & 131.1 & $\mathrm{p}<0.001$ \\
\hline Working & 3351 & 160.5 & \\
\hline \multicolumn{4}{|l|}{ Age at First Birth } \\
\hline$<18$ years & 2195 & 164.8 & \multirow[t]{2}{*}{$\mathrm{p}<0.001$} \\
\hline$>18$ years & 1662 & 145.5 & \\
\hline \multicolumn{4}{|c|}{ Institutional Delivery $(\mathrm{N}=1328)$} \\
\hline No & 620 & 115.9 & \multirow[t]{2}{*}{0.135} \\
\hline Yes & 708 & 107.3 & \\
\hline \multicolumn{4}{|c|}{ Antenatal Care $(\mathrm{ANC})^{\mathrm{a}}(\mathrm{N}=702)$} \\
\hline No Antenatal care & 127 & 102.8 & \multirow[t]{2}{*}{0.006} \\
\hline At least once & 575 & 79.2 & \\
\hline \multicolumn{4}{|c|}{ Postnatal Care $(\mathrm{PNC})^{\mathrm{a}}(\mathrm{N}=323)$} \\
\hline No & 145 & 92.1 & \multirow[t]{2}{*}{0.055} \\
\hline Yes & 178 & 74.7 & \\
\hline \multicolumn{4}{|l|}{ Sex of Child } \\
\hline Male & 2081 & 165.5 & \multirow[t]{2}{*}{$\mathrm{p}<0.001$} \\
\hline Female & 1776 & 146.0 & \\
\hline \multicolumn{4}{|c|}{ Number of children in the Household $(\mathrm{N}=3544)$} \\
\hline $1-2$ child & 1437 & 186.5 & \multirow[t]{3}{*}{$\mathrm{p}<0.001$} \\
\hline 3-4 child & 1280 & 130.5 & \\
\hline $5 \&$ above & 827 & 119.6 & \\
\hline \multicolumn{4}{|l|}{ Birth Interval $(\mathrm{N}=3037)$} \\
\hline$<2$ years & 1177 & 246.5 & \multirow[t]{3}{*}{$\mathrm{p}<0.001$} \\
\hline $2-3$ years & 1071 & 162.8 & \\
\hline$>3$ years & 789 & 96.3 & \\
\hline \multicolumn{4}{|l|}{ Birth Size $(\mathrm{N}=1258)$} \\
\hline Very small & 340 & 168.3 & \multirow[t]{3}{*}{$\mathrm{p}<0.001$} \\
\hline Smaller than average & 448 & 96.5 & \\
\hline Average or larger & 470 & 94.0 & \\
\hline \multicolumn{4}{|l|}{ Wealth Status } \\
\hline Poor & 1803 & 161.3 & \multirow[t]{3}{*}{$\mathrm{p}<0.001$} \\
\hline Middle & 877 & 164.9 & \\
\hline Rich & 1177 & 142.7 & \\
\hline \multicolumn{4}{|l|}{ Type of Residence } \\
\hline Rural & 2978 & 160.6 & \multirow[t]{3}{*}{$\mathrm{p}<0.001$} \\
\hline Urban & 879 & 141.9 & \\
\hline Total & 3857 & 155.9 & \\
\hline
\end{tabular}

${ }^{\mathrm{a}}$ Information available for only recent birth, ${ }^{\mathrm{b}}$ Excluded first birth, ${ }^{\mathrm{c}}$ Information available for those mothers who have at least one birth.

Among mother-related factors, the under-five mortality was lower for educated mothers; as they are less likely (by 6\%) to experience under-five deaths compared to the uneducated (reference category). The hazards of under-five deaths were higher among currently-working mothers compared to not working. However, the effects of both motherrelated factors, mother's education and job status, were not statistically significant.

The hazard of under-five deaths was lower (by 8\%) for women of over 18 years ( $\mathrm{HR}=0.92,95 \% \mathrm{CI}$ : $0.86-0.98)$ than that of the younger women or base category, see Table 2. The use of maternal health care services; antenatal care, institutional delivery, and postnatal care, showed insignificant relationship with the hazards of under-five mortality. Previous studies suggest that widening socioeconomic inequalities overturned the benefits of the health sector reforms, such as "Free Health Care Initiatives", and prevented the desired increase in the use of antenatal care, postnatal care and institutional delivery during 2010-2013 in Sierra Leone. ${ }^{4}$

In child-related factors, the female child was associated with lower risk of under-five mortality ( $(\mathrm{HR}=0.90,95 \% \mathrm{CI}$ : $0.84-0.96)$ than that of a male counterpart. The results show that hazards of under-five death and number of children in a household were inversely related. The households with five and more children had the lowest risk (by 65\%) 
Table 2

Hazard ratios of Under-Five Mortality by Crucial and Proximate Factors in Sierra Leone, 2013.

\begin{tabular}{|c|c|c|c|c|c|c|c|c|}
\hline Predicting Factors & Model-1 & & Model-2 & & Model-3 & & Model-4 & \\
\hline Mother Education & $\mathrm{HR}$ & $\mathrm{CI}$ & HR & CI & HR & $\mathrm{CI}$ & HR & CI \\
\hline Not Educated & 1.00 & Ref. & & & & & & \\
\hline Educated & 0.94 & $(0.79-1.10)$ & & & & & & \\
\hline \multicolumn{9}{|l|}{ Mother Occupation } \\
\hline Not Working & 1.00 & Ref. & & & & & & \\
\hline Working & 1.15 & $(0.94-1.39)$ & & & & & & \\
\hline \multicolumn{9}{|l|}{ Age at First Birth } \\
\hline$<18$ years & 1.00 & Ref. & & & & & & \\
\hline$>18$ years & $0.92^{* * *}$ & $(0.86-0.98)$ & & & & & & \\
\hline \multicolumn{9}{|l|}{ Institutional Delivery } \\
\hline No & 1.00 & Ref. & & & & & & \\
\hline Yes & 1.24 & $(0.77-1.99)$ & & & & & & \\
\hline \multicolumn{9}{|l|}{ Antenatal Care (ANC) } \\
\hline No Antenatal care & 1.00 & Ref. & & & & & & \\
\hline At least one & 0.86 & $(0.60-1.21)$ & & & & & & \\
\hline \multicolumn{9}{|l|}{ Postnatal Care (PNC) } \\
\hline No & 1.00 & Ref. & & & & & & \\
\hline Yes & 0.88 & $(0.65-1.16)$ & & & & & & \\
\hline \multicolumn{9}{|l|}{ Sex of Child } \\
\hline Male & 1.00 & Ref. & & & & & & \\
\hline Female & $0.90^{* * *}$ & $(0.84-0.96)$ & & & & & & \\
\hline \multicolumn{9}{|c|}{ Number of children in the Household } \\
\hline 1-2 child & 1.00 & Ref. & & & & & & \\
\hline 3-4 child & $0.40^{* * *}$ & $(0.34-0.46)$ & & & & & & \\
\hline $5 \&$ above & $0.35^{* * *}$ & $(0.28-0.41)$ & & & & & & \\
\hline \multicolumn{9}{|l|}{ Birth Interval } \\
\hline$<2$ years & 1.00 & Ref. & 1.00 & Ref. & & & & \\
\hline $2-3$ years & 0.90 & $(0.62-1.27)$ & $0.81 * * *$ & $(0.74-0.89)$ & & & & \\
\hline$>3$ years & $0.70^{* *}$ & $(0.49-0.98)$ & $0.53^{* * *}$ & $(0.48-0.58)$ & & & & \\
\hline \multicolumn{9}{|l|}{ Birth Size } \\
\hline Very small & 1.00 & Ref. & & & 1.00 & Ref. & & \\
\hline Smaller than average & $0.56^{* * *}$ & $(0.47-0.66)$ & & & $0.57^{* * *}$ & $(0.40-0.81)$ & & \\
\hline Average or larger & $0.55^{* * *}$ & $(0.46-0.65)$ & & & $0.60 * * *$ & $(0.43-0.83)$ & & \\
\hline \multicolumn{9}{|l|}{ Wealth Status } \\
\hline Poor & 1.00 & Ref. & & & & & 1.00 & Ref. \\
\hline Middle & 0.86 & $(0.61-1.21)$ & & & & & 0.99 & $(0.91-1.08)$ \\
\hline Rich & 0.83 & $(0.54-1.25)$ & & & & & $0.90^{* * * *}$ & $(0.84-0.97)$ \\
\hline \multicolumn{9}{|l|}{ Type of Residence } \\
\hline Rural & 1.00 & Ref. & & & & & & \\
\hline Urban & 0.96 & $(0.78-1.17)$ & & & & & & \\
\hline
\end{tabular}

$* * *=\mathrm{p}<0.001 ; * *=\mathrm{p}<0.05$; Ref. = Reference category; $\mathrm{CI}=$ Confidence interval; HR = Hazards Ratio; Model-1: adjusted HR; Model-2: Unadjusted HR; Model-3: Unadjusted HR; Model-4: Unadjusted HR.

(HR $=0.35$, 95\% CI: 0.28-0.41), and households with 2-3 children had comparatively a lower risk (HR $=0.40,95 \% \mathrm{CI}$ : $0.34-0.46)$, respectively, compared to families with fewer than three children.

The results of unadjusted hazards of crucial risk factors are given in Table 2. The birth intervals of 2-3 years and of more than 3 years were statistically significant $(\mathrm{p}<0.001$ ), see Model 2 . However, the birth interval exceeding three years showed the lowest risk $(\mathrm{HR}=0.53,95 \%$ CI: $0.48-0.58$ ) of under 5 deaths (by 57\%). Likewise, the cumulative survival of under-five children was higher among under-five children whose mothers experienced the birth inteval of more than three years see Fig. 1. However, the hazards of the birth intervals, 2-3 years and of greater than 3 years, in the adjusted model were lower than that of the unadjusted model, implying the role of confounding factors in Model 1.

The unadjusted survival rate was the lowest (by 53\%) for under-five children with smaller than average birth size ( $\mathrm{HR}=0.57,95 \% \mathrm{CI}$ : $0.40-0.81$ ), and lower (by $40 \%$ ) for children who had average or larger birth size (HR $=0.60,95 \%$, CI: $0.43-0.83$ ) compared to very small birth-size, see Table $2 \&$ Fig. 2. Fig. 1 the unadjusted-hazard of dying before completing five years of age was lower in the rich households (HR $=0.90,95 \%$ CI: 0.84-0.97) compared to the poor while the middle did not show significant effect on under-five mortality.

\section{Discussion}

The present study identified some crucial and proximate predictors of under-five mortality in Sierra Leone. Among crucial factors, only wealth status was not a significant factor of under-five survival in the extended model. It may be because of the effects of other factors, for example, birth spacing, birth size, number of children in the household, and mother's age, which would overdo the effect of wealth status. $^{12,13,22,27}$

The proximate factors examined in the study included mother's age at first birth, sex of child, and number of children in the household. Younger mothers ( $<18$ years) were predisposed to higher risk of under-five mortality. The findings are consistent with the previous research which suggests that childhood mortality is likely to be greater among mothers who are below 18 years of age and with the highest birth order. ${ }^{12,28}$

The mother-related covariates such as antenatal care, postnatal care and institutional delivery were found to be not significantly associated with under-five survival in Sierra Leone. The following empirical evidence corroborates the findings of the present study. In 2010, government started "Free Health Care Initiative (FHCI)" which aimed to dispense free medical care to pregnant women and under-five children in Sierra Leone. However, the program could not extend the outreach of maternal healthcare services to poor women for many reasons, such as 


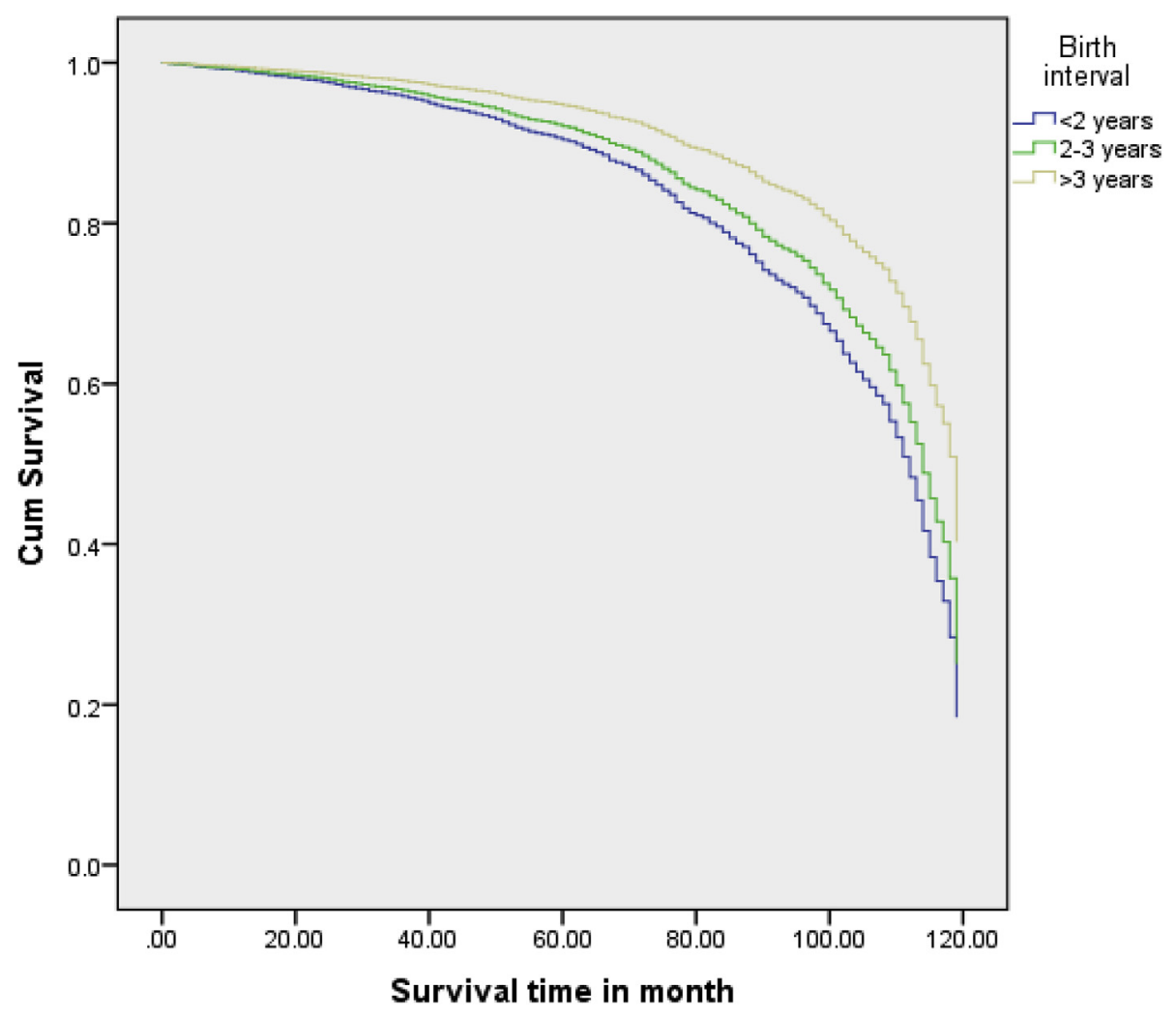

Fig. 1. Child survival by birth interval.

indirect cost, socioeconomic inequalities, rural residence, lower level of women education, and ethnic conflicts and religion. ${ }^{4}$

Moreover, the maternal education was not statistically significant. It may be because of the lower overall female education in the country, wide disparities in the education of women across rural-urban domains, and the association of the female education with social infrastructure of the country. ${ }^{4,15}$

\section{Conclusion}

This study identified the leading risk factors of under-five mortality. The essential factors are birth spacing and birth size. Both factors retain

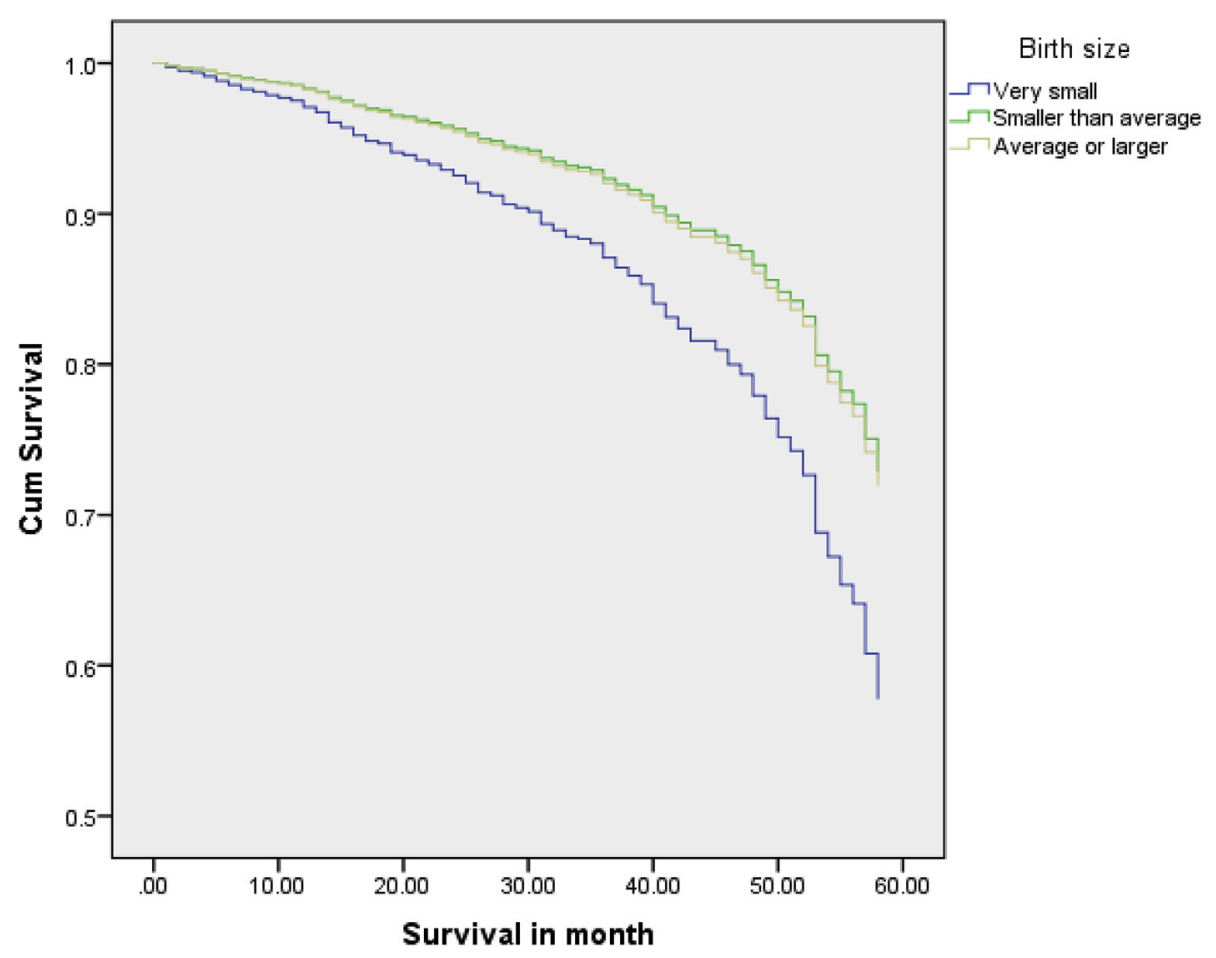

Fig. 2. Child survival by birth size. 
the prominence in the extended model. The mother's age, sex of the child, and number of children in the household are significant proximate risk factors. Given the findings of the study, we recommend for the adoption of multipronged approach in reproductive healthcare policies in Sierra Leone. The maternal health care strategies need to be synchronized with strengthening of social infrastructure. The outreach of initiatives such as "Free Health Care and Basic Package of Essential Health Services" should be extended to the poor and younger mothers. There is a need to re-evaluate the priorities of family planning programs and more focus be given to reproductive needs of younger women. The future research may be undertaken on the effects of crucial risk factors on each neonatal, infant, child, and under-five mortality separately. It may more appropriately identify the target group of healthcare interventions.

\section{Role of funding source}

We have not received any funds or financial support from any organization to undertake this research work. We acknowledge to the DHS program-USAID for providing access to download the Sierra Leone Demographic Health Survey from its website.

\section{Ethics approval}

This article does not require ethical approval because it is based on the secondary data set. The data supporting this manuscript is available publicly on the website of the DHS program (USAID). The following is the link of Sierra Leone Demographic Health survey used in this manuscript. https://dhsprogram.com/data/dataset/Sierra-Leone Standard-DHS_2013.cfm? flag $=0$.

\section{Consent to publish}

All authors have agreed to submit the manuscript to Clinical Epidemiology and Global Health for publication.

\section{Declaration of competing interest}

All authors have played multiple roles in the writing of this paper entitled "Crucial Predicting Factors of Under-Five Mortality in Sierra Leone". The following are the specific details of the contribution of each author:

1. Lubna Naz, Kamalesh Kumar, and Ifeoma Uzoma have conceptualized the paper and developed the methodology.

2. Lubna Naz has written introduction, research objectives, methods, variables description, data and sample design.

3. Kamalesh Kumar has used STATA 14 to carry out the estimation of the model and tabulated results.

4. Ifeoma Uzoma has documented results and prepared the discussion on research findings.

5. Lubna Naz has edited the results and discussion and made additions to it.

6. Lubna Naz has managed the references in Mendeley and formatted the paper as per guidelines of the journal.

7. All authors have critically evaluated the final version of the paper.

8. All authors have no conflict of interest and agreed to submit the paper to Clinical Epidemiology and Global Health.

I ensure being corresponding author that the description about the roles of authors is accurate and authors have no conflict of interest.

\section{References}

1. United Nations Children's fund. Levels \& Trends in Child Mortality. 2018; 2018https:// childmortality.org/wp-content/uploads/2018/12/UN-IGME-Child-Mortality-Report2018.pdf.

2. Amin R. Immunization coverage and child mortality in two rural districts of Sierra Leone. Soc Sci Med. 1996;42(11):1599-1604. https://doi.org/10.1016/0277. 9536(95)00024-0.

3. Bjegovic-Mikanovic V, Broniatowski R, Byepu S, Laaser U. A gap analysis of mother, new-born, and child health in west Africa with reference to the sustainable development Goals 2030. Afr J Reprod Health. 2018;22(4):123-134. https://doi.org/10. 29063/ajrh2018/v22i4.13.

4. Jalloh Boie M, Bah Jawo A, James Bai P, Sevalie S, Hann K, Shmueli A. Impact of the free healthcare initiative on wealth-related inequity in the utilization of maternal \& child health services in Sierra Leone. BMC Health Serv Res. 2019;19(352):1-15.

5. Kayombo EJ. Impact of training traditional birth attendants on maternal mortality and morbidity in Sub-Saharan African countries. Tanzan J Health Res. 2013;15(2):1-11. https://doi.org/10.4314/thrb.v15i2.7.

6. Koroma MM, Kamara SS, Bangura AE, Kamara AM, Lokossou V, Keita N. The quality of free antenatal and delivery services in Northern Sierra Leone. Health Res Pol Syst. 2017;1(49):1-15

7. Kandeh BS. Causes of infant and early childhood deaths in Sierra Leone. Soc Sci Med. 1986;23(3):297-303. https://doi.org/10.1016/0277-9536(86)90351-5.

8. Bailey M. Factors affecting infant and child mortality in rural Sierra Leone. $J$ Trop Pediatr. 1988;34:165-168.

9. Bangura S. Fighting undernutrition and child mortality in Sierra Leone. Afr J Food Nutr Sci. 2013;13(5):8188-8208.

10. Maxmen A. Sierra Leone's free health-care initiative: work in progress. Lancet. 2013;381:191-192. https://doi.org/10.1016/S0140-6736(13)60074-4.

11. Donnelly J. How did Sierra Leone provide free health care? Lancet. 2011;377:1393-1396. https://doi.org/10.1016/S0140-6736(11)60559-X.

12. Kaberuka W, Mugarura A, Tindyebwa J, Bishop DS. Factors determining child mortality in Uganda. Int J Soc Econ. 2017;44(5):633-642. https://doi.org/10.1108/ IJSE-08-2015-0201.

13. Adewuyi EO, Zhao Y, Lamichhane R. Risk factors for infant mortality in rural and urban Nigeria: evidence from the national household survey. Scand J Publ Health. 2017;45(5):543-554. https://doi.org/10.1177/1403494817696599.

14. Adetunji JA. Infant mortality in Nigeria: effects of place of birth, mother's education and region of residence. J Biosoc Sci. 1994;26(4):469-477. https://doi.org/10.1017/ S002193200002160X.

15. David SF, Susuman AS, Abduraghiem L. Vulnerable diseases affecting child mortality in Sierra Leone: emerging health issue. J Asian Afr Stud. 2012;48(3):349-369. https://doi.org/10.1177/0021909612459017.

16. Adedini SA, Odimegwu C, Imasiku ENS, Ononokpono DN, Ibisomi L. Regional variations in infant and child mortality in Nigeria: a multilevel analysis. $J$ Biosoc Sci. 2015;47(2):167-187. https://doi.org/10.1017/S0021932013000734.

17. Kayode GA, Adekanmbi VT, Uthman OA. Risk factors and a predictive model for under-five mortality in Nigeria: evidence from Nigeria demographic and health survey. BMC Pregnancy Childbirth. 2012;12(10):1-11. https://doi.org/10.1186/1471 2393-12-10.

18. McGovern ME. How much does birth weight matter for child health in developing countries? Estimates from siblings and twins. Health Econ (United Kingdom). 2019;28:3-22. https://doi.org/10.1002/hec.3823.

19. Lassi ZS, Middleton PF, Crowther C, Bhutta ZA. Interventions to improve neonatal health and later survival: an overview of systematic reviews. EBioMedicine. 2015 https://doi.org/10.1016/j.ebiom.2015.05.023.

20. Cleland JG, Sathar ZA. The Effect of birth spacing on childhood mortality in Pakistan*. Popul Stud (NY). 1984;38(3):401-418. https://doi.org/10.1080/ 00324728.1984 .10410300 .

21. Boerma JT, Bicego GT. Preceding birth intervals and child survival: searching for pathways of influence. Child Surviv Dev Ctries. 1996;23(4):243-256.

22. Biradar R, Patel KK, Prasad JB. Effect of birth interval and wealth on under-5 child mortality in Nigeria. Clin Epidemiol Glob Heal. 2019;7(2):234-238. https://doi.org/ 10.1016/j.cegh.2018.07.006.

23. Yaya S, Uthman OA, Ekholuenetale M, Bishwajit G, Adjiwanou V. Effects of birth spacing on adverse childhood health outcomes: evidence from 34 countries in subSaharan Africa. J Matern Neonatal Med. 2019:1-25. https://doi.org/10.1080/ 14767058.2019.1576623.

24. McGovern ME. How much does birth weight matter for child health in developing countries? Estimates from siblings and twins. Health Econ (United Kingdom). 2019;28(1):3-22. https://doi.org/10.1002/hec.3823.

25. Delprato M, Akyeampong K. The effect of early marriage timing on women's and children's health in sub-saharan Africa and southwest asia. Ann Glob Heal. 2017;83(34):557-567. https://doi.org/10.1016/j.aogh.2017.10.005.

26. Cox D. Regression models and life-tables. J R Stat Soc Ser B. 1972;34(2):187-220.

27. Ayele DG, Zewotir TT, Mwambi H. Survival analysis of under-five mortality using Cox and frailty models in Ethiopia. J Health Popul Nutr. 2017;36(25):1-9. https://doi. org/10.1186/s41043-017-0103-3.

28. Becher H, Müller O, Jahn A, Gbangou A, Kynast-Wolf G, Kouyaté B. Risk factors of infant and child mortality in rural Burkina Faso. Bull World Health Organ. 2004;82:265-273. https://doi.org/10.1590/S0042-96862004000400008. 